\title{
A Blockchain-based Spot Market Transaction Model for Energy Power Supply and Demand Network
}

\author{
Wei Hu, Huanhao $\mathrm{Li}^{*}$, Yawei Hu, Wenhui Yao \\ School of Economics and Management, Shanghai University of Electric Power, Shanghai 200090, China
}

Corresponding Author Email: $99030411 @$ qq.com

https://doi.org/10.18280/ejee.210112

Received: 18 December 2018

Accepted: 23 January 2019

\section{Keywords:}

spot power market, intraday time-of-use (TOU) power price, blockchain, energy power supply and demand network (EPSDN), multi-objective search algorithm

\begin{abstract}
The energy power supply and demand network (EPSDN) is difficult to be scheduled in a coordinated manner, due to the fluctuations in intraday power price. To solve the problem, this paper puts forward a blockchain-based spot market transaction model for the EPSDN, with the aim to enhance the intelligence, real-time performance and security of spot power market transactions. Specifically, intraday time-of-use (TOU) pricing mechanisms were introduced to minimize the negative impacts of intraday power price variation on the spot market; the leading influencing factors of spot power market were identified effectively among various factors through factor analysis; multiple purchase plans were optimized by the multi-objective search algorithm based on the particle swarm optimization (PSO), enabling the seller to optimize the purchase plan when multiple suppliers are available under the relaxation of control over direct power trading. On this basis, the real-time property of the transaction information was guaranteed through EPSDN-based information exchange. The case analysis shows that our transaction model outperformed the traditional centralized transaction model in transaction efficiency and security. The research findings shed new light on the operation of spot power market under partial decentralization.
\end{abstract}

\section{INTRODUCTION}

The power markets fall into several categories, namely, medium-long term market, spot market, auxiliary service market and capacity market. Among them, the spot market is an essential part of the power market system, and a strong pillar to the open, competitive and orderly operation of the power markets. As China kicks off a new round of power system reform, it is now imperative to construct a wellestablished spot power market that runs efficiently, orderly and stably, while ensuring the stable operation of the power system.

Currently, the power trading market in China is dominated by transactions planned for the medium-long run. However, the future power transactions are faced with prominent market abuse, posing a major obstacle to the construction of a modern power trading market. Meanwhile, spot power transactions, having lost in the rivalry against future power transactions, only take up a minor fraction in China's power trading market. The spot power market highlights the real-time performance and autonomy of transactions, but it is virtually impossible for the power market to make rapid response and real-time trading under the unified scheduling and planning mechanism.

Considering the constraints of source distance, energy type and power prices over spot power market, the National Development and Reform Commission and the National Energy Administration in China jointly issued the Circular Concerning Piloting the Construction of Spot Power Market in September 2017. The Circular requires market entities to implement day-ahead, intraday and real-time power trading, realize the organic connection between scheduling operations and market transactions, and form intraday time-of-use (TOU) power price with time and location features.

The blockchain is a distributed database and decentralized peer-to-peer network, featuring smart contract, distributed decision-making, coordinated autonomy, tamper-resistance security and high transparency [1,2]. With these features, the blockchain naturally fits in with the spot power market in terms of operation mode, topology and security protection, marking the future trend of market construction. Much research has been done on the blockchain application in the spot power market at home and abroad. For instance, Reference [3] constructs a transaction framework for the direct power purchase (DPP) of large consumers based on the blockchain technology, and explains how to apply the blockchain in large consumer DPP from such four aspects as market access, transaction, settlement and physical constraint. Reference [4] proposes a cross-province transaction model for generation right based on blockchain technology, and discusses the applicability of the blockchain in such transactions. References $[5,6]$ analyze the key techniques to realize blockchain-based automatic demand response from workload proof, interconnection agreement, smart contract, and information security.

Starting from the development needs of the existing power system, the above studies have explored the application of various blockchain techniques (e.g. smart contract, cooperative autonomy and point-to-point transaction) in large consumer DPP, cross-province transaction of generation right and the sales-side automatic demand response, providing valuable references to further research of blockchain-based spot market transaction model for the energy power supply and demand network (EPSDN). However, there is no report on the following factors considering the scenarios of the spot power 
market [7-10]: the structure of the spot power market, the partially decentralized real-time trading and coordinated scheduling mechanism for power energy commodities, the correlations between the intraday TOU pricing mechanism of the supplier-seller side and that of the seller-consumer side, as well as the constraints and data security of the two pricing mechanisms.

In view of the similar network topology between blockchain and spot power market system, this paper explores the structure and flow of a blockchain-based model for spot power market, and establishes an intelligent and autonomous spot power market that is partially decentralized. To mitigate the effects of intraday power price fluctuations on spot power market, the intraday TOU pricing mechanism of the supplierseller side and that of the seller-consumer side were developed in light of the formation of real-time spot power transactions and the constraints on power price. In addition, a consensus mechanism was developed using a multi-objective search algorithm based on the particle swarm optimization (PSO), with the aim to enable the supplier and the seller to achieve smart contract, help the seller optimize the purchase plan when multiple suppliers are available, make the purchase plan open and transparent, and form a "many-to-many" power purchase and sales mode reflecting the time and location features.

\section{EPSDN}

\subsection{Structure analysis}

This paper targets the spot power transactions in gridconnected EPSDN. The structure of the EPSDN is illustrated in Figure 1 below.

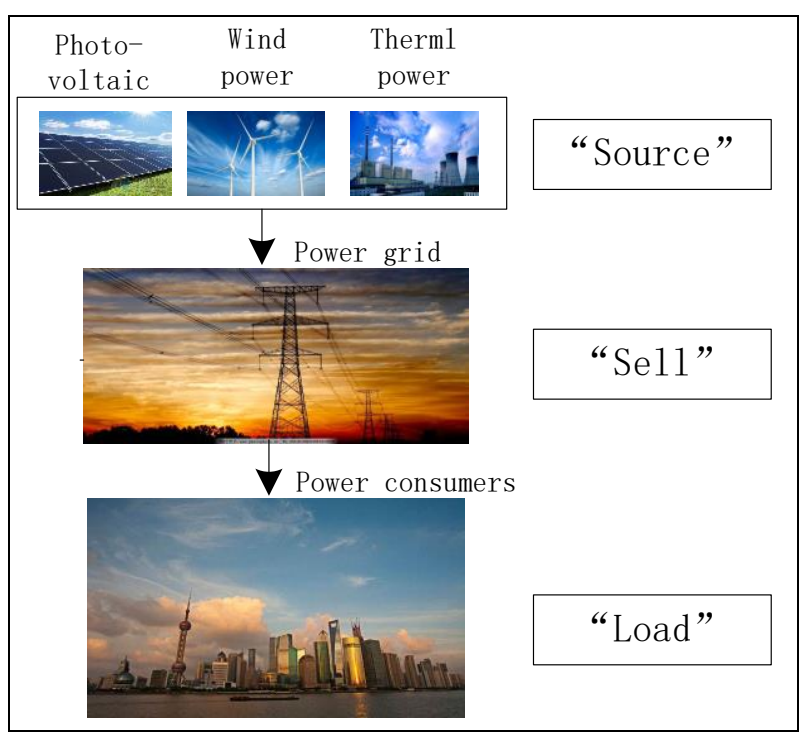

Figure 1. The structure of the EPSDN

In the above EPSDN, the supply side consists of wind, solar and thermal power plants, the sales side contains large grid and power sellers, and the consumption side involves residential, commercial and industrial consumers. The supply-demand balance of the EPSDN is achieved through the cooperation between multiple interconnected schedulable/non-schedulable supply, selling and consumption nodes. The operation mode and scheduling strategy of the EPSDN have the following features:
(1) In terms of operation mode, the EPSDN can trade spot power directly with the public grid through grid-connected operation, or achieve self-balance through self-adjustment in the off-grid state. Through spot power transactions, the EPSDN can absorb a large amount of randomly fluctuating renewable energies, thus optimizing the allocation of power resources across different regions. (2) In terms of scheduling strategy, the EPSDN supports the predictive control of distribution network scheduling commands and its own power demand through intra-network autonomy and inter-network coordination, and ensures that output/input price of each node is in line with the market clearing price.

\subsection{Blockchain-based EPSDN}

In most power systems, there are clear boundaries between the supply side, the sales side and the consumption side. However, these boundaries are increasingly obscure in the EPSDN, owing to the growing coupling between the three sides. The networking between supplier, seller and consumer have posed a serious challenge to the traditional operation and transaction mechanisms. Fortunately, the networked development of the three sides can be fully supported by a decentralized, trust-free and traceable technology known as the blockchain [11-14]. In the EPSDN, many distributed new energies are introduced to the original centralized conventional units and largescale new energy generation, and the system scheduling and operation are shifting from the centralized mode to the distributed mode. The decentralized feature of the blockchain technology adapts well to these distribution trends of the EPSDN. In a blockchain-based scheduling system, the power supply/demand and price of each node in the power system are shared in real time, allowing each node to determine its transaction volume and price according to the shared information. In this way, it is possible for the power system to realize intelligent scheduling and operation. Figure 2 presents a blockchain-based EPSDN.

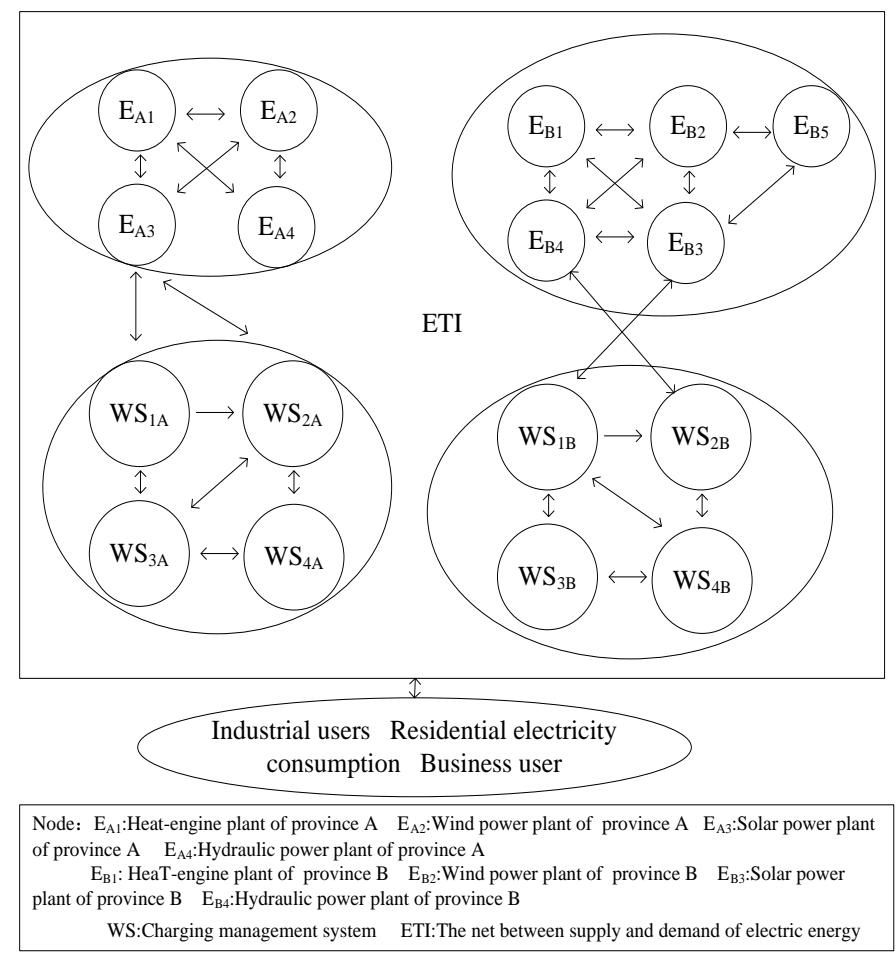

Figure 2. The blockchain-based EPSDN 


\section{BLOCKCHAIN-BASED SPOT POWER MARKET TRANSACTION MODEL}

\subsection{Traditional pricing mechanism of spot power transactions}

At present, the setting of intraday TOU power prices is constrained by (1) clean energy subsidies; (2) grid power, geographical location, time and weather; (3) sellers' preferential policies; (4) maintenance cost and transmission/distribution cost of power lines.

The formulation rules for current intraday TOU power prices are as follows: dividing each day into several equal time periods, analyzing the price difference between the time periods according to the historical power demand on one day in a province, and setting different power prices depending on the power demand of each time period in that day. The on-grid price of a power plant in the time period $T(a \sim b)=$ $t(a) \sim t(b)$ can be expressed as:

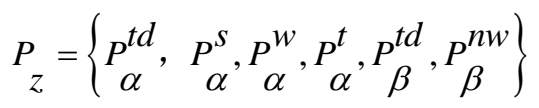

where, $P_{\alpha}^{t d}, P_{\alpha}^{s}, P_{\alpha}^{w}$ and $P_{\alpha}^{t}$ are the power prices of conventional energy, solar power, wind power and hydropower plants within the province, respectively; $P_{\beta}^{t d}$ and $P_{\beta}^{n w}$ are the power prices of conventional and new energy power plants in other provinces, respectively. Considering that power sellers now prefer to purchase clean energy, the power purchase cost of a seller can be expressed as:

$$
\mathrm{P}_{w s}=P_{m}+P_{z}+P_{j}
$$

where, $P_{m}$ is the unit price of clean energy power; $P_{z}$ is the ongrid price; $P_{j}$ is the transmission/distribution cost. To improve consumer satisfaction, the seller can flexibility adjust the unit profit $P_{(q)}$ under the premise of making profit. Thus, the power purchase cost of a consumer can be expressed as:

$$
P_{v}=P_{w s}+P_{(q)}
$$

where, $P_{w s}$ and $P_{(q)}$ are the cost and unit profit of the seller, respectively. The above analysis shows that the seller has a relatively simple profit model; the purchase cost of the seller may vary because clean energy cannot be connected to the grid all day long, which affects the purchase price of the consumer; the intraday TOU price is highly volatile as the spot transactions are conducted through the unified trading center; the consumer lacks diverse purchase plans.

The cause analysis on the intraday TOU price provides a reference for the formulation of spot power transaction plan under the blockchain structure. Since the transaction nodes are of equal status in the decentralized blockchain, the author put forward a novel intraday TOU pricing mechanism to solve the price fluctuation, formulate real-time multi-option purchase plan, and enhance spot power trading efficiency.

\subsection{Double-sided intraday TOU power pricing mechanism}

During power consumption, the price at the "supplier-seller" side consists of the generation price and the transmission/distribution price, while the price at the "seller- consumer" side covers the seller cost and seller profit. From the operation of spot power market, the EPSDN can absorb a large amount of power generated from new energy plants through power transactions. As a supplement to the balance mechanism of market-based power supply, the spot power trading can partially alleviate new energy loss, diversify the commodities in the market, improve the competition and adjustment of power market transactions, and ultimately promote the bilateral transactions among supplier, seller and consumer.

The new round of power system reform partially relaxed the control over power production and consumption plans, without sacrificing the stable operation of the power system, and developed the power market into a decentralized "multiseller, multi-buyer" transaction platform. On the "supplierseller" side, the eligible producers and sellers can now determine the transaction quantity and price via bilateral or multilateral transactions; on the "seller-consumer" side, the sellers are permitted to determine the transaction quantity and price through bilateral negotiation with large or common consumers. Finally, a win-win, rational pricing mechanism was established under the market mechanism for intraday TOU power price on both the "supplier-seller" side and the "seller-consumer" side. Figure 3 shows the power purchase and sales process of supplier, seller and consumer in intraday power price transactions.

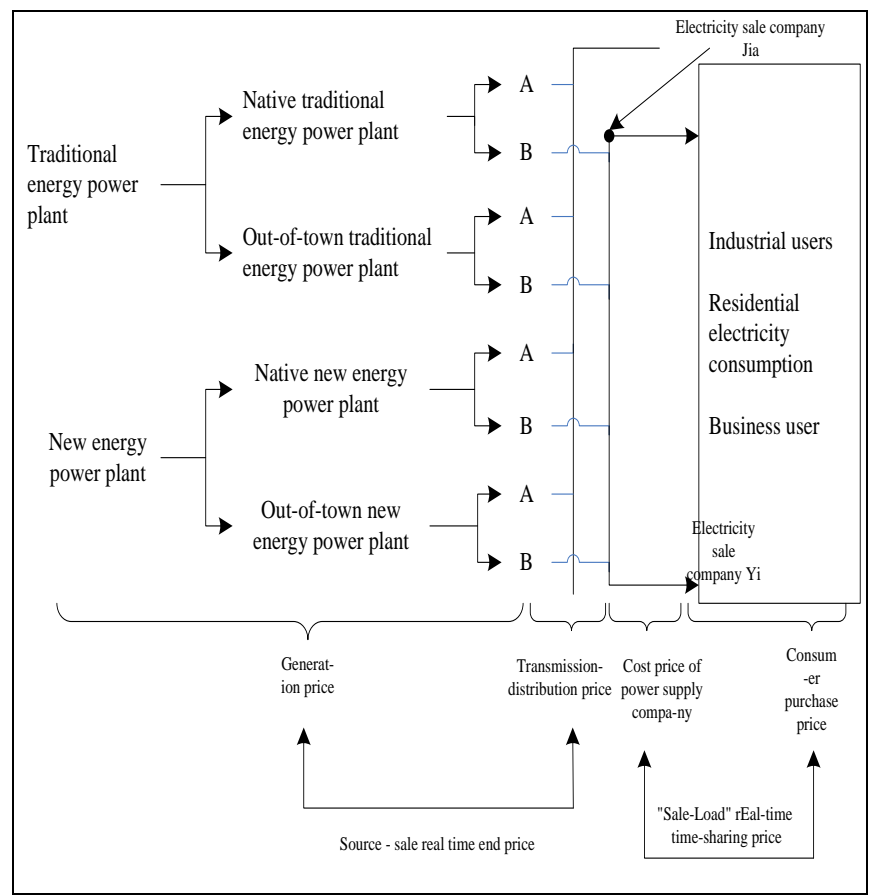

Figure 3. Purchase and sales process of intraday TOU power price

Under the competitive power purchase/sales market of multiple sellers and buyers, the double-sided pricing mechanism provides the supplier, seller and consumer in intraday transactions with multiple options and fast response to the market situation. Considering the decentralized, trustfree and traceable features of the blockchain technology, it is necessary to create a partially or fully decentralized power supply and demand transaction model for the spot power transactions in the EPSDN based on the blockchain technology, in which all energy nodes are of equal status. 


\subsection{Power supply and demand trading blockchain (SDTB)}

The SDTB can be mathematically described as:

$$
M_{S D M B}=(M, S D T A)
$$

where, $\mathrm{M}$ is the main blockchain; SDTA is the supply and demand trading algorithm. The data structure of the SDTB is shown in Figure 4 below.

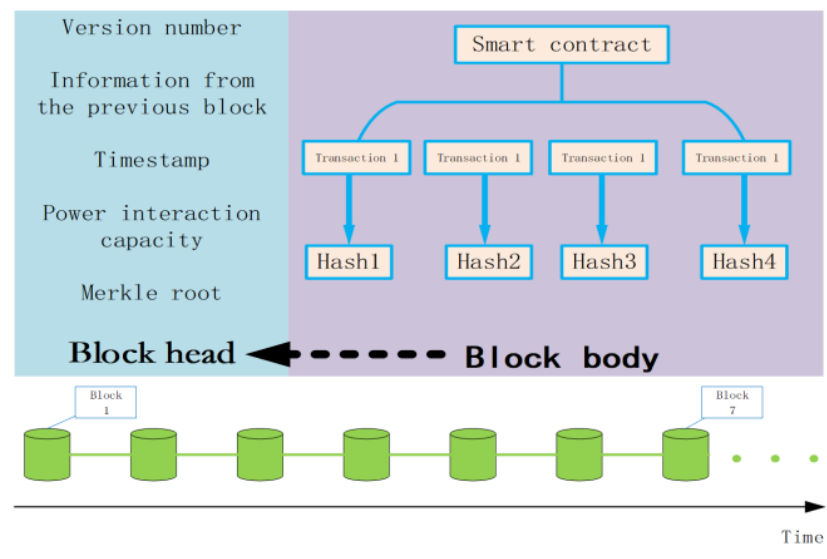

Figure 4. Data structure of the SDMB

The storage of transaction records is essential to the security of the transaction information in the EPSDN. When the trading algorithm completes operation, a new block should form, and the demand node (DN) should acquire the information of the corresponding supply node (SN) and transmit the transaction information to the SDTB. Based on the delegated proof-ofstake (DPOS) consensus, the SDTA was designed as follows:

1) All SNs and DNs broadcast their own transaction statuses, and identify information like ID to the EPSDN at regular intervals of $\Delta t$.

2) Each node receives the information and records it in its own data storage center.

3) At $0.1 \Delta t$ after the reception, each node broadcasts its own transaction status: <TradeIntention, ID, t, q, l, p> to the entire network, where $\mathrm{t}$ is the type of node, $\mathrm{q}$ is the transaction quantity, 1 is the node location and $\mathrm{p}$ is the unit price of transaction.

4) Through the smart contract, each node calculates the weights of the nodes on the other side according to Table 1, and arranges them in descending order. Then, the node with the maximum weight is selected and its information is transmitted to the SDMB: <TradeResult, ID, t, q, l, p>, where $\mathrm{a}$ is the weight of the selected node.

Table 1. Parameters of energy nodes

\begin{tabular}{ccc}
\hline Parameter & $\begin{array}{c}\text { Proportiona-lity } \\
\text { coefficient }\end{array}$ & $\begin{array}{c}\text { Basic Coefficient } \\
\text { Value }\end{array}$ \\
\hline Generating capacity c & $\pi_{c}$ & 0.6 \\
Renewable energy $\mathrm{r}$ & $\pi_{r}$ & 0.7 \\
Node location l & $\pi_{r}$ & 0.5 \\
Transaction price $\mathrm{p}$ & $\pi_{q}$ & 0.5 \\
Government subsidy & $\pi_{a}$ & 0.6 \\
coefficient a & & 0.6 \\
Power generation & $\pi_{s}$ & 0.6 \\
stability s &
\end{tabular}

\subsection{Operation analysis of spot power trading market}

The operation efficiency of spot power market is the core issue in the market construction. Here, the factors reflecting the market operation efficiency are summarized from the spot power transactions and the common factors are listed in Table 2 below.

Table 2. Observable common factors in spot power market

\begin{tabular}{cc}
\hline Serial number & Specific factors \\
\hline 1 & Generating capacity \\
2 & The degree of market concentration \\
3 & Market efficiency \\
4 & Government subsidy coefficient \\
5 & Lerner index \\
6 & High price winning rate \\
7 & Power generation stability \\
8 & The relevance between transaction price and \\
9 & concentration degree \\
10 & Transaction price \\
& Bid winning rate in spot transactions \\
\hline
\end{tabular}

These factors were processed by factor analysis, a statistical technique to extract the special ones out of many factors. Specifically, a few special factors were identified and their relationship with observable factors were described, considering the internal dependence of the correlation coefficient moments (or covariance moments) among multiple observable factors. The factor model with $q$ common factors can be described as the matrix equation below:

$$
\left[\begin{array}{l}
X_{1} \\
X_{2} \\
\cdots \\
X_{p}
\end{array}\right]-\left[\begin{array}{l}
\mu_{1} \\
\mu_{2} \\
\ldots \\
\mu_{p}
\end{array}\right]=\left[\begin{array}{l}
l_{11} \ldots l_{14} \ldots l_{1 q} \\
l_{21} \ldots l_{24} \ldots l_{2 q} \\
\ldots \\
l_{p 1} \ldots l_{p 4} \ldots l_{p q}
\end{array}\right]\left[\begin{array}{c}
F_{1} \\
F_{2} \\
\ldots \\
F_{q}
\end{array}\right]+\left[\begin{array}{l}
\varepsilon_{1} \\
\varepsilon_{2} \\
\ldots \\
\varepsilon_{p}
\end{array}\right]
$$

where, $\quad X=\left[X_{1}, X_{2}, X_{3}, X_{4}, \ldots X_{p}\right]^{T}$ is a P-dimensional stochastic observable variable that satisfies $E(X)=\mu$, with $E(\cdot)$ being an expectation function and $\mu=$ $\left[\mu_{1}, \mu_{2}, \mu_{3}, \mu_{4} \ldots \mu_{p}\right]^{T} ; F=\left[F_{1}, F_{2}, F_{3}, F_{4}, \ldots F_{q}\right]^{T}$ is a random vector consisting of $q(q \leqslant p)$ common factors; $\varepsilon=$ $\left[\varepsilon_{1}, \varepsilon_{2}, \varepsilon_{3}, \varepsilon_{4}, \ldots \varepsilon_{p}\right]^{T}$ is the measurement error vector corresponding to $X$, representing the part of variable $X$ cannot be explained by the latent variable; $L=\left(l_{i j}\right)_{p \times m}$ is a factor load matrix, with its element $l_{i j}$ being the load of the $i$-th observable variable $X_{i}$ on the $j$-th common factor.

It is very important to evaluate the operation efficiency of spot power market. The evaluation not only measures the market efficiency, but, more importantly, discloses the main influencing factors of the operation efficiency. Besides, the key influencing factors of spot power market can be derived from the common factors obtained in factor analysis. These factors should be highlighted in the future transactions between the market players. Considering the importance of these special factors, these players can write them into the smart contract of blockchain to create a more efficient spot power transaction market. 


\subsection{Blockchain-based spot power market trading model}

The spot power market faces various operational constraints. For example, the power needs to be transmitted across different provinces, because the supply-demand relationship varies from province to province; lots of power are lost in the long distance trans-provincial transmission, pushing up the transmission cost. Meanwhile, the spot power transactions are dominated by large consumers and sellers. The transaction price is often determined through the bilateral game between these players. Obviously, the above transaction model is far from being the global optimal plan. In addition, the spot power market needs to deal with other problems like protecting the ID information of both sides and computing the real-time power price. To solve these constraints, the blockchain mechanism was adopted to ensure that the nodes in the market complete real-time, transparent and effective spot transactions in chronological order. As a result, a blockchain-based spot power market trading model was established (Figure 5) based on the EPSDN [15-18], TOU pricing mechanism, SDTB and spot power market operation analysis.

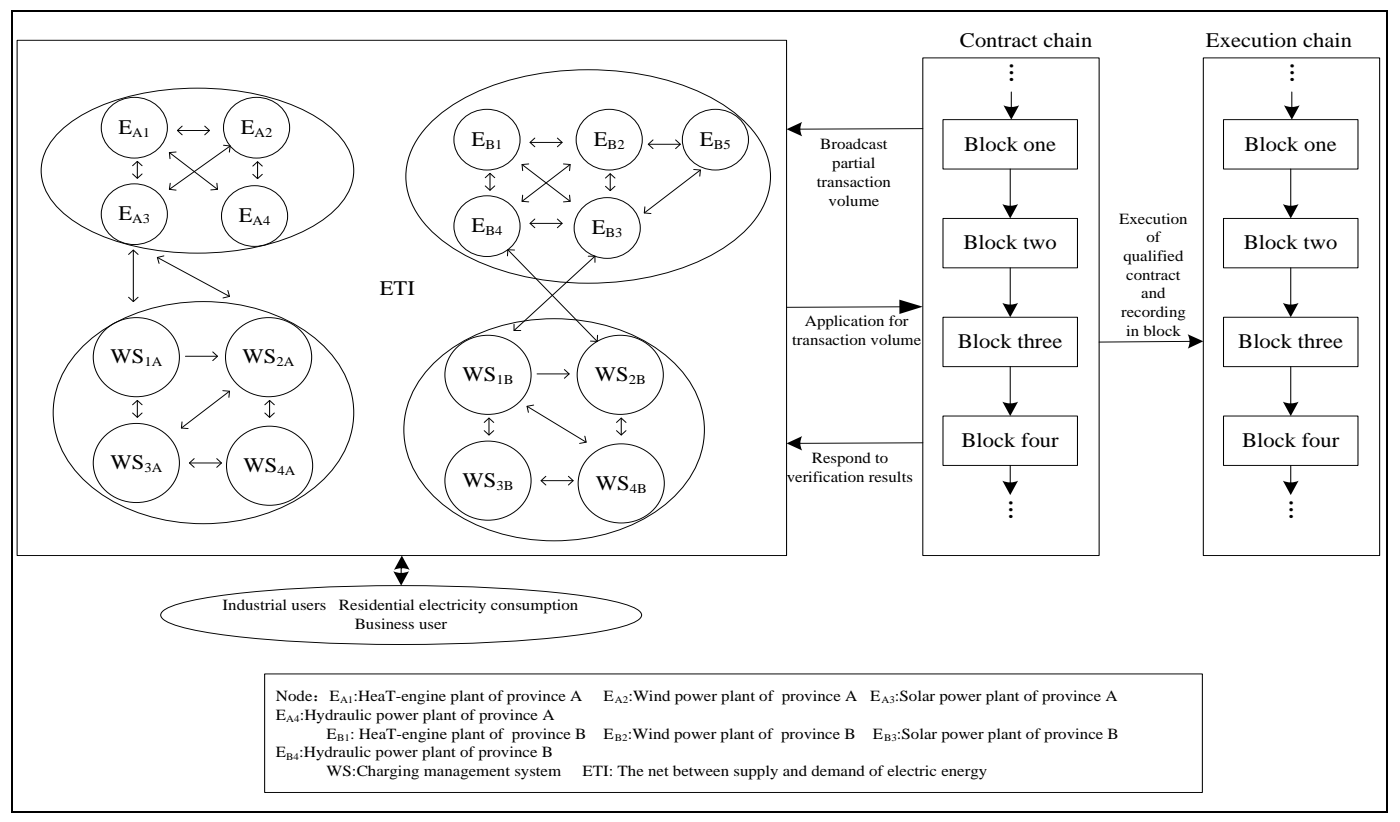

Figure 5. Blockchain-based real-time spot power transaction model

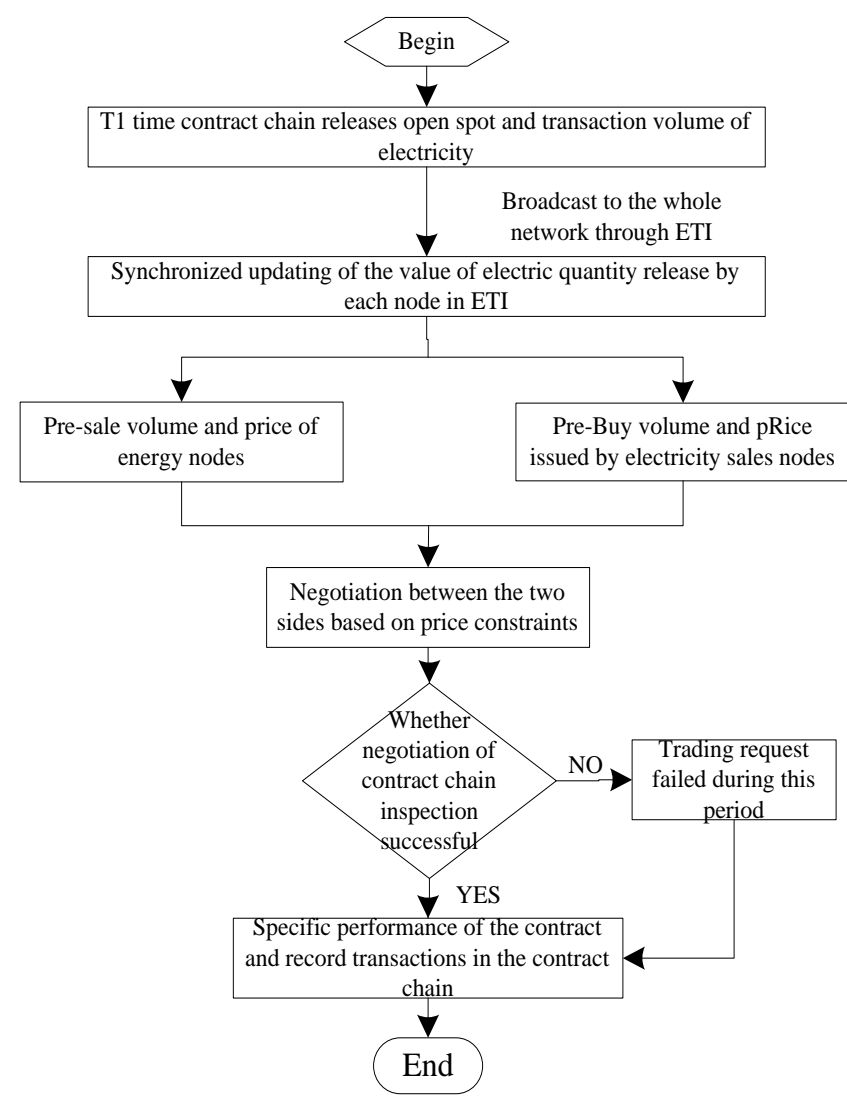

Figure 6. Blockchain-based spot power trading process
As shown in Figure 5, the blockchain-based real-time spot power transaction model for the EPSDN is about the spot power transactions between provinces $\mathrm{A}$ and $\mathrm{B}$. There are two blockchains in the model, namely, LH1 (contract chain) and LH2 (execution chain). The blockchain technology provides the technical support to the model, while the EPSDN offers the information exchange platform. During the operation, the contract chain LH1 broadcasts the permitted transaction value for a given period to the EPSDN system, receives the initial transaction plan from the EPSDN, verifies the executability of the plan, and then returns the verification result to the EPSDN. The verified plan will be executed by the execution chain LH2. It can be seen from the established model that the coordination between the contract chain LH1, the execution chain LH2 and the EPSDN is the key to the stable operation of spot power market transactions. The blockchain-based spot power trading process is explained in Figure 6.

In the blockchain, it takes a fixed length of time to reach a consensus and generate a new block. To eliminate the delay in existing planned relaxation of the control over direct power trading, the amount of power to be traded in a given period was determined through negotiation between the nodes on the contract chain (the time needed to reach a contract $\Delta t=1 \mathrm{~h}$ ), in light of the scheduling features of the EPSDN. Taking the period from $T_{i}$ to $T_{i}+\Delta t$ as an example: (1) The contract chain LH1 computes the open trading amount for the target period, which starts from the effective moment $T_{t e}=T_{i}+$ $3 \Delta t$, according to the line load plan of the target area, and provides the transmission/distribution power price of the area. 
(2) The suppliers and sellers in the EPSDN update the information in a synchronous manner. (3) Each supplier releases the initial sales amount and price, while each seller releases the initial purchase amount and price; the two sides hold a negotiation under the price constraints; the contract chain verifies if the negotiation is successful, and records the negotiation results; then, the execution chain implements the results and records the implementation process. (4) Before the moment $T_{i}+2 \Delta t$, the power transaction block is generated from the negotiation results in the contract chain: the consensus on the point-to-point smart contract is broadcasted to the entire network, and coupled with the actual transaction information in the previous period to form a new block. (5) The EPSDN reports the expected transaction information generated at $T_{i}+2 \Delta t$ to the contract chain LH1, and the latter will verify the transaction information, laying the basis for the next transaction.

There is no fully centralized node in the blockchain-based real-time spot power transaction model. Instead, all energy nodes are of the same status. The normal operation is maintained through the consensus mechanism. Under the blockchain structure, all nodes in the spot power market can reach spot power price plan, transaction plan and transaction priority allocation plan in chronological order through negotiation, making the real-time transaction fair and effective. Moreover, the transaction security is fully protected because the spot market transactions are complete and tamper-resistant thanks to the distributed data storage and traceability of the blockchain.

\section{BLOCKCHAIN-BASED SPOT POWER MARKET OPERATION}

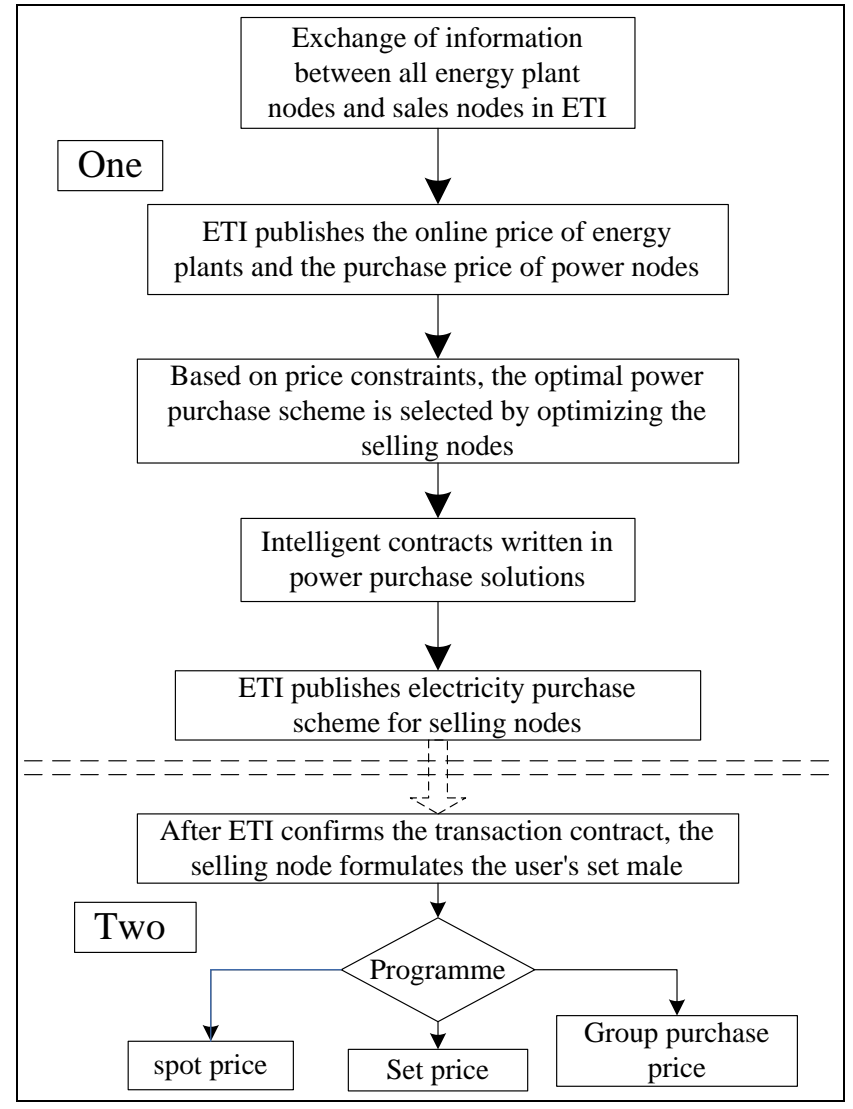

Figure 7. The purchase plans offered by sellers and the consumer's plan selection process
Our real-time spot power transaction model was established based on the intraday TOU power pricing mechanism and the blockchain-based EPSDN (Figure 2). The introduction of the blockchain framework promotes the mutual trust between trading entities, enhances trading timeliness and accuracy, and shortens the time of spot power transactions, alleviating the fluctuations resulted from the grid-access of new energy sources like wind power and solar power. The fluctuations are further suppressed by the contract chain's real-time broadcasting of the power quantity. In the blockchain-based spot power transaction model, a seller can prepare its purchase strategy based on PSO-based multi-objective search algorithm and include it in the smart contract, solving the pricing issue. On the consumer side, a consumer can select the optimal purchase plan from the various plans offered by sellers. The selection process is explained in Figure 7.

Taking the purchase plans of each consumer as the objectives, the selection of the optimal purchase plan can be considered as a multi-objective optimization problem. Here, this problem is solved by the PSO-based multi-objective search algorithm. The optimal plan was determined by the algorithm under the "multi-seller, multi-buyer" condition of spot power market. For the said multi-objective optimization problem, the random solutions were computed iteratively to find the optimal particle. The particles can be updated by the following formulas:

$V^{k+1}=\alpha V^{k}+a_{1}\left(P_{i d}^{k}-X^{k}\right)+a_{2}\left(P_{g d}^{k}-X^{k}\right)$

$X^{k+1}=X^{k}+V^{k+1}$

where, $X$ is the particle position; $V$ is the particle velocity; $k$ is the number of iterations; $\alpha$ is the inertia coefficient; $a_{1}$ and $a_{2}$ are constants; $P_{i d}^{k}$ and $P_{g d}^{k}$ are the best-known individual and global positions, respectively.

Taking Province A as an example, the PSO-based multiobjective search algorithm was adopted to identify the optimal purchase plan offered by a seller in that province. A total of 16 power plants were competing to sell power to the seller in Province A. The 16 plants can be divided evenly into 4 categories by the energy type, that is, each category has 4 plants ( 1 from Province A and 3 from the other three provinces). The on-grid price and transmission/distribution price were different between the four provinces. Under the price constraints, a mathematical model was established by the PSO-based multi-objective search algorithm, where $P, R$ and $P_{d}$ are respectively the on-grid price, the available power quantity and mean transmission/distribution cost of each plant. The three variables obey the following functional relationships:

$$
\begin{aligned}
& \min P_{e}=\sum_{i=4}^{4} p_{i} * Y \\
& \max R_{x}=\sum_{i=1}^{4} R_{i} * Y \\
& \text { s.t. } \frac{\sum_{i=1}^{4}\left(P_{i}+P_{d i}\right) * R_{i}}{\sum_{i=1}^{4} R_{i}} \leq 0.50
\end{aligned}
$$


where, $P_{e}$ is the power price of each plant; $R_{x}$ is the available power quantity of each plant; $P_{d i}$ is the mean transmission/distribution cost of each plant; $Y$ is the selected plant. The iterations of the PSO-based multi-objective search algorithm puts the mean power price at RMB 0.5 yuan $/ \mathrm{kWh}$. Under market constraints, the optimization algorithm was written in the smart contract with the minimum power price that satisfies the seller's purchase demand, enabling rapid and accurate spot power transactions.

\section{CASE ANALYSIS}

In the blockchain-based spot power market, the sellers in different provinces have the same competitive status. As mentioned before, the PSO-based multi-objective search algorithm $[19,20]$ can select the optimal purchase plan from the various plans offered by multiple sellers, solving the delayed release of purchase information and enhancing the efficiency of spot power transactions. In this section, the algorithm was simulated on MATLAB to obtain the optimal purchase plan. The simulation process is explained below.

Table 3. On-grid prices of four types of power plants in the eight provinces (Unit: RMB yuan/kWh)

\begin{tabular}{lcccc}
\hline & 1 & 2 & 3 & 4 \\
\hline A province & 0.65 & 0.57 & 0.31 & 0.36 \\
B province & 0.65 & 0.56 & 0.33 & 0.32 \\
C province & 0.55 & 0.45 & 0.35 & 0.37 \\
D province & 0.55 & 0.40 & 0.13 & 0.25 \\
E province & 0.60 & 0.40 & 0.25 & 0.30 \\
F province & 0.60 & 0.55 & 0.25 & 0.25 \\
G province & 0.50 & 0.48 & 0.28 & 0.29 \\
H province & 0.58 & 0.58 & 0.30 & 0.27 \\
\hline
\end{tabular}

Table 4. Available power quantities of four types of power plants in the eight provinces (Unit: RMB yuan/MWh)

\begin{tabular}{lcccc}
\hline & 1 & 2 & 3 & 4 \\
\hline A province & 1500 & 1400 & 800 & 400 \\
B province & 1200 & 1000 & 500 & 0 \\
C province & 0 & 1400 & 650 & 1800 \\
D province & 1450 & 1150 & 1800 & 2000 \\
E province & 800 & 1000 & 500 & 1500 \\
F province & 2000 & 1200 & 850 & 1200 \\
G province & 1800 & 1450 & 1500 & 600 \\
H province & 0 & 750 & 600 & 500 \\
\hline
\end{tabular}

Table 5. Mean transmission/distribution costs of four types of power plants in the eight provinces (Unit: RMB yuan/kWh)

\begin{tabular}{lcccc}
\hline & 1 & 2 & 3 & 4 \\
\hline A province & 0.08 & 0.08 & 0.08 & 0.08 \\
B province & 0.18 & 0.18 & 0.18 & 0.18 \\
C province & 0.10 & 0.10 & 0.10 & 0.10 \\
D province & 0.23 & 0.23 & 0.23 & 0.23 \\
E province & 0.21 & 0.21 & 0.21 & 0.21 \\
F province & 0.09 & 0.09 & 0.09 & 0.09 \\
G province & 0.15 & 0.15 & 0.15 & 0.15 \\
H province & 0.16 & 0.16 & 0.16 & 0.16 \\
\hline
\end{tabular}

Model: A real-time power price model was established for eight provinces, denoted as Provinces $\mathrm{A} \sim \mathrm{H}$, involved in a spot power transaction. In the model, 1, 2, 3 and 4 respectively stand for solar power plant, wind power plant, hydropower plant, and conventional energy power plant. The transaction data are presented in Tables 3-5.

The data in Tables 3-5 were written in matrix form according to the simulation mode in the PSO-based multiobjective search algorithm, and adopted for the simulation under the optimization plan and transaction constraints. The simulation results are presented in Figure 8, where the $\mathrm{x}$-axis is the total power quantity purchased by the non-inferior solution and the $y$-axis is the mean power price (RMB yuna/kWh) of the non-inferior solution. Six types of purchase plans (non-inferior solutions) were obtained through the simulation and written as the following matrix, in which each row stands for a type of non-inferior solution and X-Y refers to the position of the non-inferior solution.
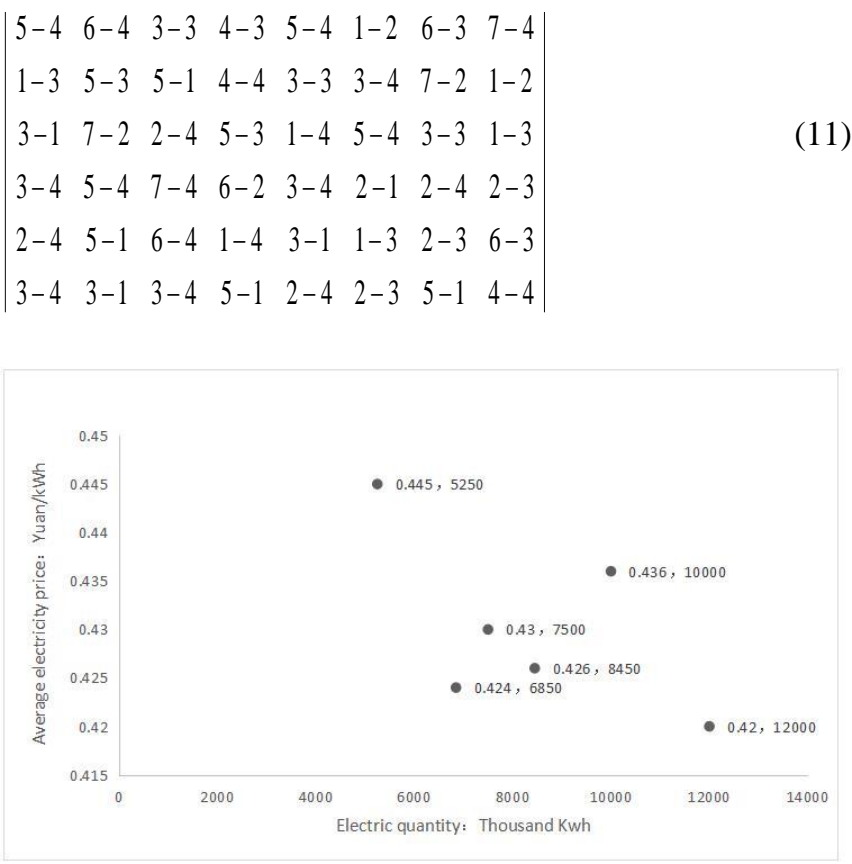

Figure 8. Simulation results (the distribution of non-inferior solutions in the target space)

The total power quantity and mean power price of each plan were computed according to the position of the actual power price in the matrix.

Type 1 plans have a total power quantity of $6,850 \mathrm{MWh}$ and a mean power price of RMB 0.424 yuan $/ \mathrm{kWh}$;

Type 2 plans have a total power quantity of $8,450 \mathrm{MWh}$ and a mean power price of RMB 0.426 yuan $/ \mathrm{kWh}$;

Type 3 plans have a total power quantity of $10,000 \mathrm{MWh}$ and a mean power price of RMB 0.436 yuan $/ \mathrm{kWh}$;

Type 4 plans have a total power quantity of 5,250MWh and a mean power price of RMB 0.445 yuan $/ \mathrm{kWh}$;

Type 5 plans have a total power quantity of 7,500MWh and a mean power price of RMB 0.430 yuan $/ \mathrm{kWh}$;

Type 6 plans have a total power quantity of $12,000 \mathrm{MWh}$ and a mean power price of RMB 0.420 yuan $/ \mathrm{kWh}$.

Then, the seller can select the optimal purchase plan from the 6 types of plans according to the real-time power price and power demand. The purchase plan selected by our algorithm is the optimal choice under the market price constraints, which promotes the healthy development of spot power market and ensures the diversity and intelligence of the seller's power purchase. 


\section{CONCLUSIONS}

The development of the EPSDN spot market is accompanied by the growth of transaction entities and the surge in the number of transactions, making it more difficult to manage spot power transactions. This calls for an effective trading model to simplify the transaction process. Focusing on the operation mode of spot power market under blockchain structure, this paper turns the transactions in the spot power market into chains and integrates them with the smart contract, thus ensuring the reliability and intelligence of the transactions. The TOU power pricing mechanism was employed to reduce price volatility and maintain transaction stability. After analyzing the operation of spot power market, the special factors with prominent impacts on the market were identified, and written into the smart contract by market players, laying the basis for a more efficient spot power market. In addition, the PSO-based multi-objective search algorithm was adopted, enabling the seller to select the optimal real-time purchase plan, and was promoted to the power price transactions in "multiseller, multi-buyer" spot power market. On this basis, the seller can offer various purchase plans to consumers, giving a powerful boost to the intraday TOU pricing mechanism of the supplier-seller side and that of the seller-consumer side. However, the price game between transaction entities under the blockchain structure is yet to be discussed.

Considering the gradual opening of China's power market, the future research will improve the price game between transaction entities by the smart contract, and further optimize the blockchain-based spot market transaction model for the EPSDN, so as to enhance the reference value of our findings to the research on blockchain applications in the spot power market.

\section{ACKNOWLEDGEMENT}

This paper is made possible thanks to the generous support from the Humanities and Social Sciences Project of Chinese Ministry of Education (Grant No.: 17YJCZH062).

\section{REFERENCES}

[1] Zeng M, Cheng J, Wang YQ, Li YF, Yang YQ, Dou JY. (2017). Primarily research for multi module cooperative autonomous mode of energy internet under blockchain framework. Proceedings of the CSEE 37(13): 3672-3681. http://doi.org/10.13334/j.0258-8013.pcsee.162432

[2] Yli-Huumo J, Ko D, Choi S, Park S, Smolander K. (2016). Where is current research on blockchain technology-A systematic review. PLoS ONE 11(10): e0163477. http://doi.org/10.1371/journal.pone.0163477

[3] Ouyang X, Zhu XQ, Ye L, Yao JG. (2017). Preliminary applications of blockchain technique in large consumers direct power trading. Proceedings of the CSEE 37(13): 3737-3745.

http://doi.org/10.13334/j.0258-8013.pcsee.170370

[4] Shi QS, Liu K, Wen M. (2017). Interprovincial generation rights trading model based on blockchain technology. Electric Power Construction 38(9): 15-23. http://doi.org/10.3969/j.issn.1000-7229.2017.09.003

[5] Li B, Zhang J, Qi B, Li DZ, Shi K, Cui GY. (2017). Block chain: Supporting technology of demand side resources participating in grid interaction. Electric Power Construction 38(3): 1-8.

http://doi.org/10.3969/j.issn.1000-7229.2017.03.001

[6] Yang XD, Zhang YB, Lu JJ, Zhao B, Huang FT, Qi J, Pan HW. (2017). Blockchain-based automated demand response method for energy storage system in an energy local network. Proceedings of the CSEE 37(13): 37033716. http://doi.org/10.13334/j.0258-8013.pcsee.17038

[7] Green RJ, Newbery DM. (1992). Competition in the British electricity spot market. Journal of Industrial Economics 100(5): 929-953. https://doi.org/10.2307/2950646

[8] Ederer N. (2015). The market value and impact of offshore wind on the electricity spot market: Evidence from Germany. Applied energy 154(9): 805-814. https://doi.org/10.1016/j.apenergy.2015.05.033

[9] Paschen M. (2016). Dynamic analysis of the German day-ahead electricity spot market. Energy Economics 59(9): 118-128. https://doi.org/10.1016/j.eneco.2016.07.019

[10] Frade P, Vieira-Costa J, Osório G. (2018). Influence of wind power on intraday electricity spot market: A comparative study based on real data. Energies 11(11): 2974. https://doi.org/10.3390/en11112974

[11] Sikorski JJ, Haughton J, Kraft M. (2017). Blockchain technology in the chemical industry: Machine-tomachine electricity market. Applied Energy 195(4): 234246. https://doi.org/10.1016/j.apenergy.2017.03.039

[12] Fairley P. (2017). Blockchain world-Feeding the blockchain beast if bitcoin ever does go mainstream, the electricity needed to sustain it will be enormous. IEEE Spectrum 54(10): 36-59. http//doi.org/10.1109/MSPEC.2017.8048837

[13] Cheng S, Zeng B, Huang YZ. (2017). Research on application model of blockchain technology in distributed electricity market. IOP Conference Series: Earth and Environmental Science 93(1): 012065. http://doi.org/10.1088/1755-1315/93/1/012065

[14] Kang J, Yu R, Huang X, Maharjan S, Zhang Y, Hossain E. (2017). Enabling localized peer-to-peer electricity trading among plug-in hybrid electric vehicles using consortium blockchains. IEEE Transactions on Industrial Informatics 13(6): 3154-3164. https://doi.org/10.1109/TII.2017.2709784

[15] Wu FF, Varaiya PP, Hui RSY. (2015). Smart grids with intelligent periphery: An architecture for the energy internet. Engineering 1(4): 436-446. http//doi.org/10.15302/J-ENG-2015111

[16] Zhou K, Yang S, Shao Z. (2016). Energy internet: The business perspective. Applied Energy 178: 212-222. http://doi.org/ 10.1016/j.apenergy.2016.06.052

[17] Xue YS. (2015). Energy internet or comprehensive energy network? Journal of Modern Power Systems and Clean Energy 3(3): 297-301. http://doi.org/10.1007/s40565-015-0111-5

[18] Zore Ž, Čuček L, Širovnikb D, Pintarič ZN, Kravanja Z. (2018). Maximizing the sustainability net present value of renewable energy supply networks. Chemical Engineering Research and Design 131(3): 245-265. http://doi.org/10.1016/j.cherd.2018.01.035

[19] Hashemi Y, Shayeghi H, Moradzadeh M, Safari A. (2016). Design of hybrid damping controller based on multi-target gravitational search optimization algorithm in a multi-machine power system with high penetration 
of PV park. Journal of Central South University 23(5): 1163-1175. http://doi.org/10.1007/s11771-016-0366-7

[20] Zhao Y, Wang T, Qin W, Zhang XH. (2018). Improved Rao-Blackwellised particle filter based on randomly weighted particle swarm optimization. Computers \& Electrical Engineering 71: 477-484.

http://doi.org/10.1016/j.compeleceng.2018.07.055 